EGU2020-4630

https://doi.org/10.5194/egusphere-egu2020-4630

EGU General Assembly 2020

(c) Author(s) 2020. This work is distributed under

the Creative Commons Attribution 4.0 License.

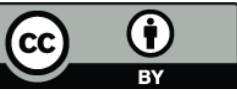

\title{
Systemic risks emerging from global climate hotspots and their impacts on Europe
}

\author{
Franziska Gaupp ${ }^{1}$ and Jana Sillmann ${ }^{2}$ \\ ${ }^{1}$ International Institute for Applied Systems Analysis, Austria \\ ${ }^{2}$ Center for International Climate Research (CICERO), Norway
}

In a globalized world, Europe is increasingly affected by climate change events beyond its borders that propagate through our interconnected systems impacting the socio-economic welfare in Europe. The REmote Climate Effects and their Impact on European sustainability, Policy and Trade (RECEIPT) project uses a novel stakeholder-driven storytelling approach that maps representative connections between remote climate hazards such as droughts or hurricanes and European socioeconomic activities in the agricultural, finance, development, shipping and manufacturing sectors. As part of RECEIPT, this work focuses on systemic risks in global climate risk hotspots and their knock-on effects on the European economy. In five stakeholder workshops, expert elicitation methods are used to identify and map sector- and storyline-specific systemic risks: interlinkages between different events, hidden causes and consequences, potential feedback loops, uncertainties and other systemic risk characteristics will be investigated. A special focus lies on "gray rhino" events, "foreseeable random surprises" that follow clear warning signs but are only known to a smaller group of people. Results reveal sector-specific "topographies of risk" within the storylines identified by stakeholders. 